\title{
Fast Synthesis of Hydroxymethylfurfural from Levoglucoseno- ne by Mixing with Sulphuric Acid and Heating in a Microtube Reactor
}

\author{
Xin HUANG $^{1}$, Daiki MitsUYAMA ${ }^{1}$, Shinji KUdO ${ }^{1,2^{*}}$, and Jun-ichiro HAYASHi ${ }^{1,2}$ \\ ${ }^{1}$ Interdisciplinary Graduate School of Engineering Sciences and ${ }^{2}$ Institute for Materials Chemistry and Engineering, Kyushu \\ University, 6-1 Kasuga Koen, Kasuga, 816-8580, Japan
}

\begin{abstract}
Hydroxymethylfurfural (HMF) is a promising platform chemical in future bio-based chemical industry for synthesis of a variety of furan derivatives. Studies on the HMF synthesis have focused mainly on saccharides as the feedstock. Recently, levoglucosenone (LGO), anhydrosugar available from cellulose pyrolysis, has been identified as an alternative feedstock, which can be converted to HMF under milder conditions only with acid and water as catalyst and solvent, respectively. To further explore the potential of this reaction, in this study, we demonstrated the HMF synthesis below $100^{\circ} \mathrm{C}$ within a few minutes at high yields. The employment of microtube reactor and high concentration sulfuric acid as catalyst was effective, leading to the highest HMF yield of $61.5 \%-\mathrm{C}$ with the reaction selectivity over $80 \%$. Kinetic analysis revealed that rapid heating after mixing $L G O$ with the catalytic aqueous solution was essential to supress side reaction that generates degradation products from LGO. The reaction with glucose or fructose as feedstock under same conditions resulted in poor HMF yield.
\end{abstract}

\section{Introduction}

Hydroxymethylfurfural (HMF) has vast potential to be an important building block in future bio-based chemical industry, and, therefore, often referred to as "sleeping giant" (Mukherjee et al., 2015). As evidenced by many studies, HMF can be converted to chemicals used in a wide range of markets/applications such as fuels, solvents, polymers, and pharmaceuticals (van Putten et al., 2013). The industrial scale production has already been started by some companies. On the other hand, the price is still high as a platform chemical to be competitive with petroleum derived chemicals (E4tech, RE-CORD, and WUR, 2015). Although there are many factors affecting the price, most importantly, it is necessary to reduce the cost of chemicals needed to convert the feedstock into HMF. In other words, development of more efficient process is required.

Saccharides are generally employed as feedstock for HMF in researches and industries. Fructose is the best option for achieving higher yields. Glucose is also converted to HMF basically after isomerization to glucose. Polysaccharides including cellulose or lignocellosic biomass can be used as the feedstock but need depolymerisation that causes lower yields in general. As summarised in recent review studies (van Putten et al., 2013; Qi et al., 2014; Mukherjee et al., 2015), much effort has been made for achieving the high HMF yield through development of catalytic and solvent systems. However, even for fructose and using costly catalyst and solvent, it is hard to achieve near-complete conversion of the feedstock to HMF. This is due to the occurrence of sidereactions in the course of multi-step removing of three water molecules from saccharides. The complexity of reaction thus has been a drawback of HMF production from conventional resources.

Levoglucosenone (LGO) is a compound available from cellulose. Pyrolysis of cellulose under acid catalysis selectively produces LGO (Kawamoto et al., 2007; Cao et al., 2015; Kudo et al., 2017; Ye et al., 2017; Huang et al., 2019a). Although it is still expensive, recently, a commercial scale production has been started in Australia, and the production method is intensively studied by researchers for making it more accessible. The target product from LGO in current market is limited mainly to dihydrolevoglucosenone, which is used as solvent (Sherwood et al., 2014), but extensive studies have revealed the potential to be a type of platform chemical similarly to HMF (Krishna et al., 2018). Recent studies (Krishna et al., 2016; He et al., 2017; Huang et al., 2019b) have identified LGO as an alternative feedstock for HMF. LGO is readily isomerises to HMF under acid catalysis even in water. Because of simplicity in chemistry, the reaction is relatively selective and occurs at milder conditions compared to saccharide conversion to HMF.

With the purpose of contribution to development of more efficient process, in the present study, we investigated HMF production at atmospheric pressure in a short reaction time using $\mathrm{LGO}$ as feedstock. A

* Corresponding author: shinji_kudo@cm.kyushu-u.ac.jp 
microtube was employed as the reactor, which was important to achieve high HMF yields.

\section{Experimental}

\subsection{Materials}

LGO was purchased from Circa Group, Australia. Sulphuric acid, HMF, levulinic acid (LA), and formic acid (FA) were purchased from Wako Pure Chemical Industries and used as catalyst or standard reagent for quantification of reaction products.

\subsection{Reaction}

Experiments of aqueous phase LGO conversion were performed with the setup schematically shown in Figure 1. $\mathrm{H}_{2} \mathrm{SO}_{4}$ aqueous solution $(1.0-4.9 \mathrm{~mol} / \mathrm{L})$ was fed into PEEK tube with inner diameter of $0.5 \mathrm{~mm}$. The solution passed through $\mathrm{T}$-mixer, heater $\left(60-90^{\circ} \mathrm{C}\right)$, cooler, and then flowed out as the reaction product. After confirming steady flow at the outlet, feeding of pure LGO was started. LGO was readily dissolved in $\mathrm{H}_{2} \mathrm{SO}_{4}$ aqueous solution at the mixer without forming separated phases and then heated up. The reaction time was controlled by the flow rate and length of tube in oil bath $(10 \mathrm{~m})$. The flow ratio between two solutions was adjusted to achieve LGO concentration of $0.1 \mathrm{~mol} / \mathrm{L}$. The $\mathrm{LGO}$ conversion experiment was also carried out with a batch system. LGO was added to $5 \mathrm{~mL}$ of $\mathrm{H}_{2} \mathrm{SO}_{4}$ aqueous solution $(4.9 \mathrm{~mol} / \mathrm{L})$ in a pressure tube with stirring bar. The tube was immersed in a water bath for temperature control immediately after the LGO addition. The reaction was quenched with an iced water.

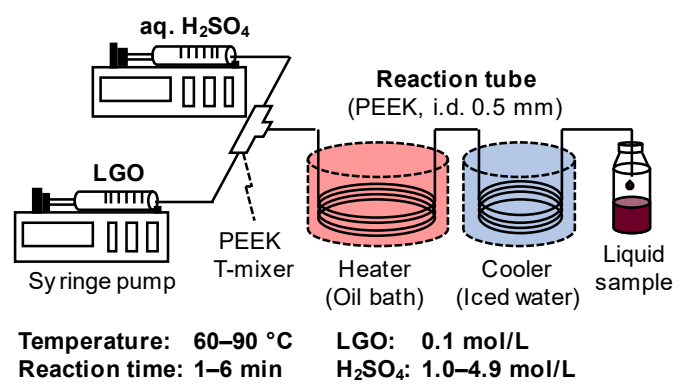

Figure 1. Experimental setup used for aqueous phase conversion of LGO in microtube reactor

\subsection{Product analysis}

The product liquid was diluted with water and subjected to composition analysis with high-performance liquid chromatography (HPLC, Shimadzu LC-20 prominence series). The molecules were separated by a BioRad Aminex $87 \mathrm{H}$ column and detected by refractive index detector and photo diode array detector. Details about the analytical conditions can be found elsewhere (Huang et al., 2019b). LGO forms dehydrated product (DH) when dissolved in water. The conversion between LGO and DH is fast and determined thermodynamically to the equilibrium. In accordance with previous studies (Krishna et al., 2016; Huang et al., 2019b), the conversion of LGO $\left(X_{\mathrm{LGO}}\right)$ was calculated from concentrations of $\mathrm{DH}$ as well as LGO before and after the reaction. Degradation products (DPs) were defined as compounds other than LGO, DH, HMF, LA and FA. Since those were basically only compounds detected in HPLC analysis, DPs were apparently large molecules such as humins. The yield of DPs was calculated from the carbon balance.

\section{Results and Discussion}

\subsection{LGO conversion with high concentration sulphuric acid in microtube reactor}

The effect of $\mathrm{H}_{2} \mathrm{SO}_{4}$ concentration on the reaction was investigated at $90^{\circ} \mathrm{C}$, and the result is presented in Figure 2. The formation of HMF under atmospheric pressure was confirmed. The rates of LGO conversion and HMF formation were improved with the $\mathrm{H}_{2} \mathrm{SO}_{4}$ concentration. Krishna et al. (2016) first demonstrated the formation of HMF from LGO in the aqueous phase reaction. They used $0.05 \mathrm{~mol} / \mathrm{L}$ of $\mathrm{H}_{2} \mathrm{SO}_{4}$ and needed more than $1 \mathrm{~h}$ to achieve a high $\mathrm{HMF}$ yield at $125^{\circ} \mathrm{C}$. Their kinetic analysis (available only for the reaction with $0.05 \mathrm{~mol} / \mathrm{L}$ of $\mathrm{H}_{2} \mathrm{SO}_{4}$ ) indicated that higher temperature was preferred for $\mathrm{HMF}$ yield. At low temperature such as $100^{\circ} \mathrm{C}$ the $\mathrm{HMF}$ yield was much below $20 \%$ even with 100 min reaction, and further extension of reaction time was less effective. Our previous study (Huang et al., 2019b) using a solid acid catalyst needed harsher conditions.
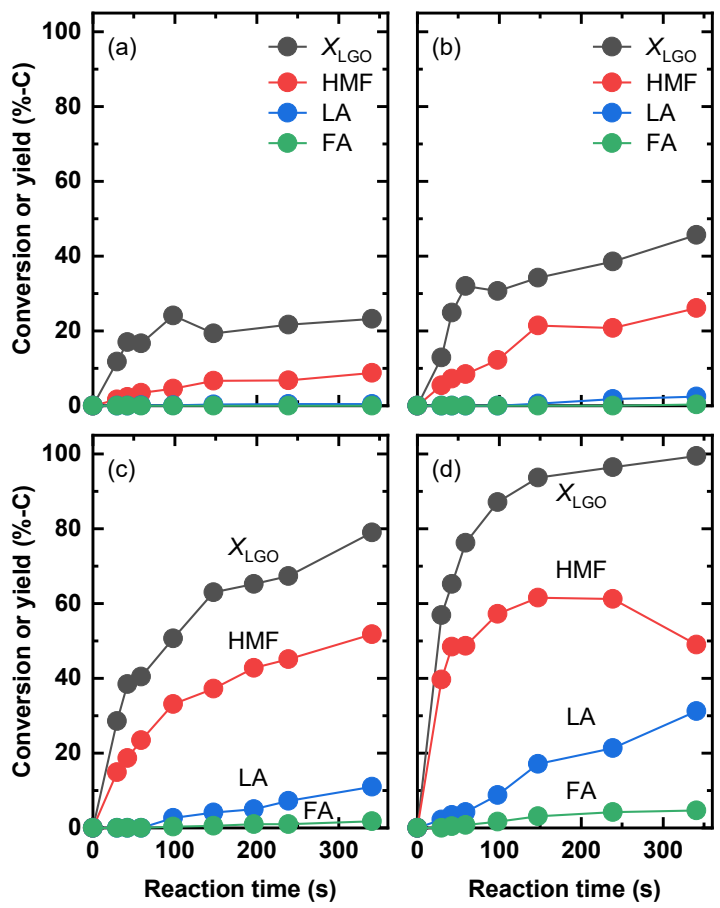

Figure 2. LGO conversion in microtube reactor. Conditions: LGO $0.1 \mathrm{~mol} / \mathrm{L}, 90^{\circ} \mathrm{C}, \mathrm{H}_{2} \mathrm{SO}_{4}$ (a) $1.0 \mathrm{~mol} / \mathrm{L}$, (b) 2.2 $\mathrm{mol} / \mathrm{L}$, (c) $3.5 \mathrm{~mol} / \mathrm{L}$, and (d) $4.9 \mathrm{~mol} / \mathrm{L}$

The present results revealed the possibility of $\mathrm{HMF}$ production with the substantial yield even below $100^{\circ} \mathrm{C}$ if the $\mathrm{H}_{2} \mathrm{SO}_{4}$ concentration was sufficiently high. The highest LGO yield on a carbon basis was $61.5 \%$-C. The 
total yield of HMF, LA, and FA, indicating the reaction selectivity, was over $80 \%$ at $147-340 \mathrm{~s}$ with $4.9 \mathrm{~mol} / \mathrm{L}$ $\mathrm{H}_{2} \mathrm{SO}_{4}$. The formation of LA and FA was clearly observed in the reaction with $\mathrm{H}_{2} \mathrm{SO}_{4} \geq 3.5 \mathrm{~mol} / \mathrm{L}$. This is a type of side-reaction for the HMF production, but LA is also considered as a promising building block (Rackemann et al., 2011).

The experiment was carried out with conventional feedstock such as glucose and fructose under the same conditions with LGO conversion using $4.9 \mathrm{~mol} / \mathrm{L} \mathrm{H}_{2} \mathrm{SO}_{4}$ (Figure 3). The yield of HMF was very low. For glucose, the yield was below $1 \%-\mathrm{C}$ even at $340 \mathrm{~s}$. As mentioned above, they are essentially good feedstock for HMF. Shimanouchi et al. (2016) and Muranaka et al. (2017) showed high yields of HMF in aqueous phase conversion of fructose or glucose in a microtube reactor. When applied biphasic system with water-insoluble organic solvent, the HMF yield was well above $70 \%$ at $180^{\circ} \mathrm{C}$ because HMF formed in aqueous phase was extracted to the organic solvent before converted to LA. However, the present result demonstrates that LGO is better as feedstock for achieving high HMF yield under atmospheric pressure with short reaction time. This is likely due to the simplicity of reaction, which involves only ring-opening and closing via acyclic intermediate with no loss of atoms from the molecule (Krishna et al., 2016) and therefore has low activation energy. On the other hand, HMF formation from saccharides consists of multi-step reactions. Fructose dehydration is initiated by protonation, followed by a number of protonationdehydration-deprotonation, resulting in HMF (Yang et al., 2012). Dehydration of glucose needs one more step, isomerization to fructose, although HMF forms directly from glucose in parallel under catalysis of Brønsted acid (Saha and Abu-Omar, 2014). Intermediates rich in active functional groups are precursor to undesired humins.
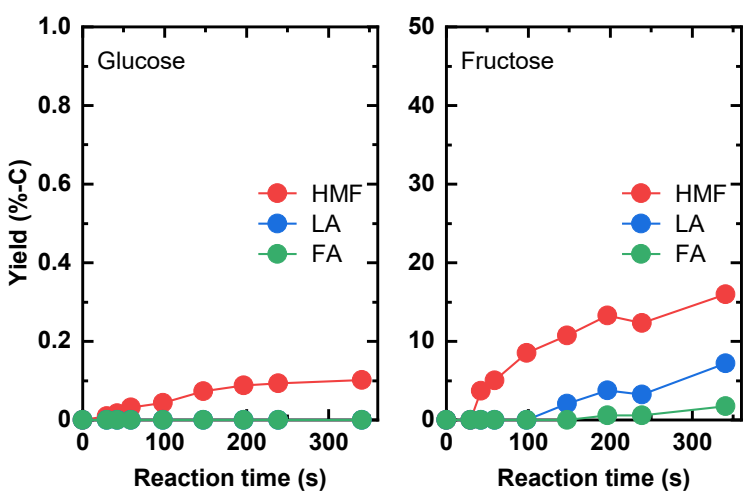

Figure 3. Glucose or fructose conversion in microtube reactor. Conditions: glucose or fructose $0.1 \mathrm{~mol} / \mathrm{L}, 90^{\circ} \mathrm{C}$, and $\mathrm{H}_{2} \mathrm{SO}_{4}$ $4.9 \mathrm{~mol} / \mathrm{L}$.

\subsection{Kinetic analysis}

For better understanding of the LGO conversion with high concentration $\mathrm{H}_{2} \mathrm{SO}_{4}(4.9 \mathrm{~mol} / \mathrm{L})$, the experiment was carried out at different temperatures. The result is shown in Figure 4 as data points. The formation of HMF was confirmed in all the experiments at $60-90^{\circ} \mathrm{C}$. The HMF yield profile had a maximum above $80^{\circ} \mathrm{C}$ mainly due to the conversion to LA and FA.

The experimental data was kinetically analysed according to the reaction scheme 1 . LGO is sequentially converted to HMF and then LA + FA. LGO and HMF also form DPs. The scheme is similar to that in our previous study (Huang et al., 2019b), which effectively represented the LGO conversion under acid catalysis, but lacks in the pathways of furfural formation and degradation since it was not observed in this study. The analysis assumed first order reaction with respect to the reactant as represented by eq. (1):

$$
r_{i}=k_{0, i} \exp \left(-E_{i} / \mathrm{R} T\right) C_{j}
$$

where $k_{0, i}$ and $E_{i}$ are frequency factor and activation energy of reaction $i(=1-4)$, respectively. $\mathrm{R}, T$, and $C_{j}$ are gas constant, temperature, and concentration of $j(=\mathrm{LGO}$, HMF, FA, and LA), respectively. To focus on the reaction under catalysis of high concentration $\mathrm{H}_{2} \mathrm{SO}_{4}$, the influence of its concentration was not considered in the calculation. Kinetic parameters $\left(k_{0, i}\right.$ and $\left.E_{i}\right)$ were optimized by regression analysis to the best fit between experimental and calculated yields.

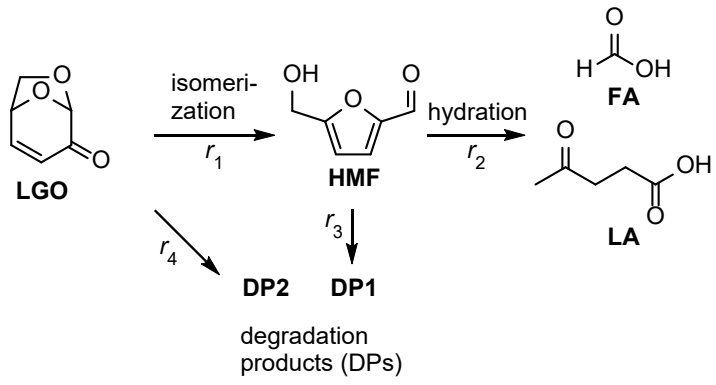

Scheme 1. Reaction pathways used for kinetic analysis from LGO to HMF, LA, FA, and DPs

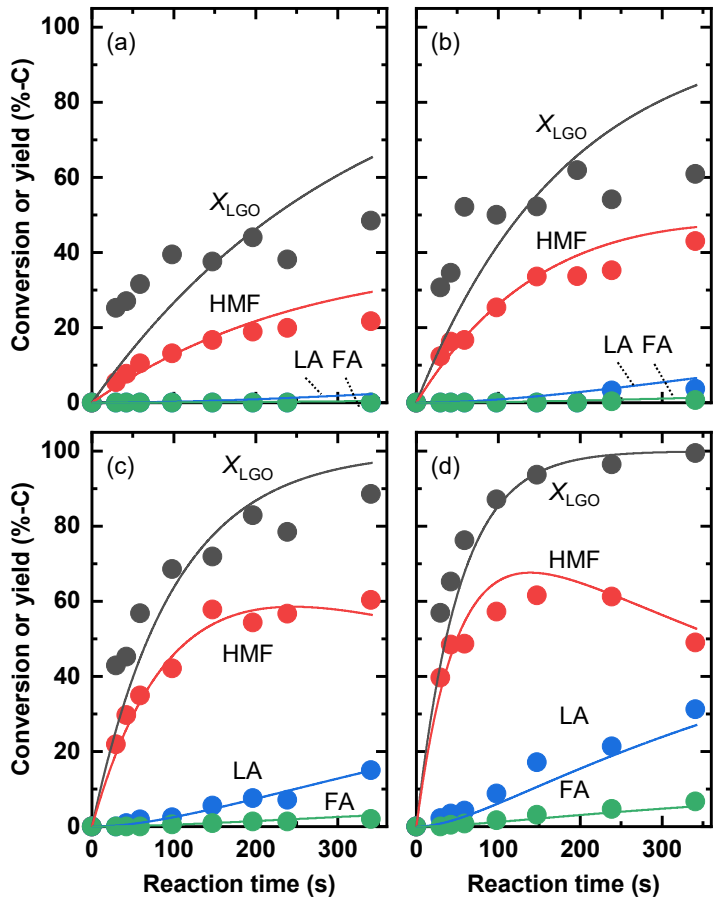

Figure 4. LGO conversion in microtube reactor. Conditions: LGO $0.1 \mathrm{~mol} / \mathrm{L}, \mathrm{H}_{2} \mathrm{SO}_{4} 4.9 \mathrm{~mol} / \mathrm{L}$, (a) $60^{\circ} \mathrm{C}$, (b) 
$70^{\circ} \mathrm{C}$, (c) $80^{\circ} \mathrm{C}$, and (d) $90^{\circ} \mathrm{C}$. Data points represent the experimentally obtained results. Lines represent the conversion and yields calculated with kinetic parameters.

Table 1 lists kinetic parameters obtained from the analysis. The magnitude relation among the parameters is in line with reported one (Huang et al., 2019b). Figure 5 shows HMF yield calculated with the parameters as functions of temperature and reaction time. The yield maximum was observed at high temperature and short reaction time area. Apparently, the yield could be over $80 \%$-C, although this was not examined experimentally since high pressure reaction was outside the scope of this research. At any temperature, the HMF yield first increased and then decreased with reaction time. This was due to consumption of HMF by $r_{2}$ and $r_{3}$. However, the contribution of $r_{3}$ was far smaller than that of $r_{2}$. The ratio of rate constants, $k_{2} / k_{3}$, was at the order of $10^{4}$ even at $140^{\circ} \mathrm{C}$. The formation of DP1 was thus negligible, and therefore HMF was selectively converted to LA and FA. An important observation was difference in the maximum HMF yield by reaction temperature. This is explained by the formation of DP2. As shown in Figure 6 and indicated by the low value of $E_{4}, \mathrm{DP} 2$ yield was higher at lower temperature. The ratio of $k_{1} / k_{4}$, at $60,70,80$, and $90^{\circ} \mathrm{C}$ was $0.98,1.8,3.3$, and 5.8, respectively. DP2 is thus major product rather than HMF at low temperatures. The similar DP2 yields at short reaction time (Figure 6) regardless of the difference in $k_{1} / k_{4}$ are resulted from increase in $r_{4}$ with temperature.

Table 1. Kinetic parameters calculated with experimental data in Figure 4, assuming Scheme 1 and eq. (1) under conditions of LGO $0.1 \mathrm{~mol} / \mathrm{L}$ and $\mathrm{H}_{2} \mathrm{SO}_{4} 4.9 \mathrm{~mol} / \mathrm{L}$

\begin{tabular}{ccccc}
\hline & $k_{0, i}$ & & $E_{i}$ \\
\cline { 1 - 2 } \cline { 5 - 5 }$k_{0,1}$ & $\left(\mathrm{~L} / \mathrm{mol} / \mathrm{min}, \times 10^{-10}\right)$ & & & $(\mathrm{kJ} / \mathrm{mol})$ \\
$k_{0,2}$ & $2.60 \times 10$ & & $E_{1}$ & 79.4 \\
$k_{0,3}$ & $1.99 \times 10^{-5}$ & & $E_{2}$ & 43.8 \\
$k_{0,4}$ & $1.28 \times 10^{6}$ & & $E_{3}$ & 176 \\
\cline { 5 - 6 } & $1.17 \times 10^{-8}$ & & $E_{4}$ & 20.0 \\
\hline
\end{tabular}

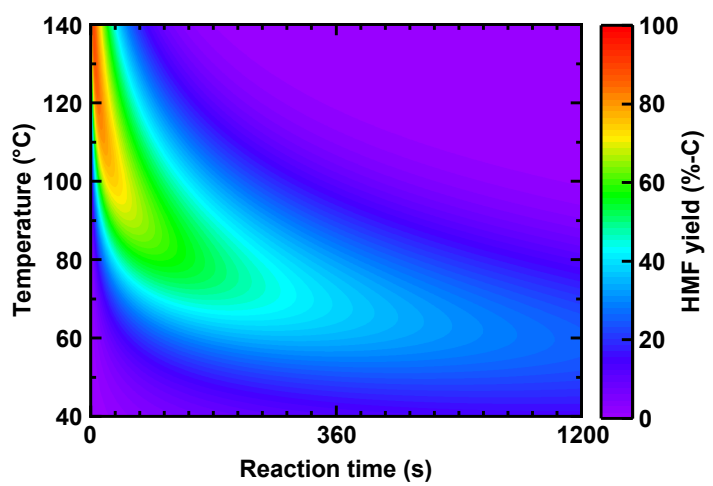

Figure 5. HMF yield map calculated with kinetic parameters, assuming validity of the parameters at extended range of temperature $\left(40-140^{\circ} \mathrm{C}\right)$

\subsection{Comparison with batch system}

Overall trend found in the kinetic analysis indicated importance of precise control of temperature and reaction time for achieving high selectivity toward the target reaction. The reaction at low temperature is in particular unfavourable because it causes loss of LGO. This problem can be apparent in the reaction with batch system, which needs long time for heating the solution to desired temperature, depending on conditions. The reaction in a batch reactor was simulated by calculation with kinetic parameters. Before heating, the temperature (room temperature; $20^{\circ} \mathrm{C}$ ) was kept constant for $0-10 \mathrm{~min}$, which assumed time for reactor setup, and then increased to $90^{\circ} \mathrm{C}$ at slow heating rate of $1-10^{\circ} \mathrm{C} / \mathrm{min}$ (Figure 7 (a)).

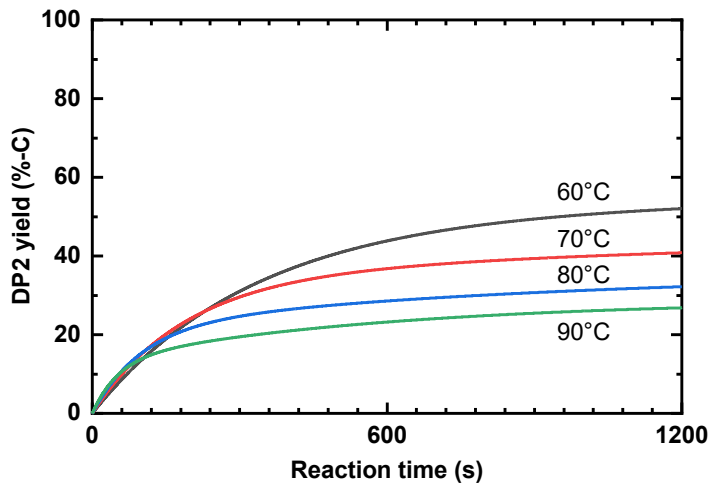

Figure 6. DP2 yield calculated with kinetic parameters .

(a)

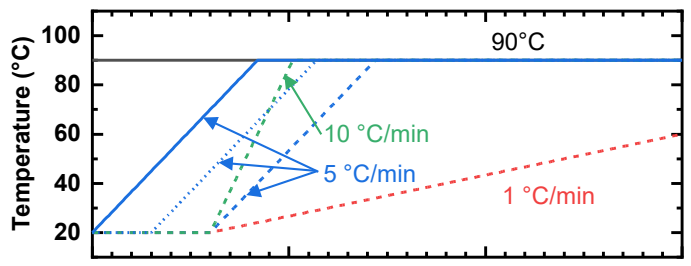

(b)

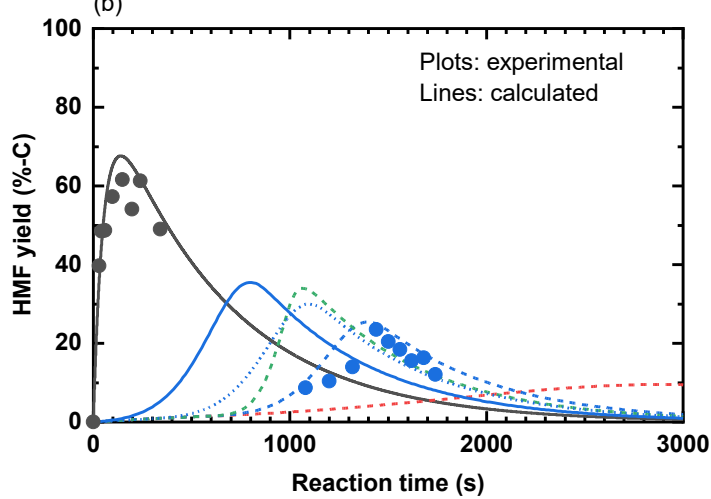

Figure 7. LGO conversion in a batch reactor: (a) temperature profile and (b) HMF yield. Black plots and line show the results in experiment and calculation with microtube reactor. The batch experiment was carried out with $10 \mathrm{~min}$ holding time at $20^{\circ} \mathrm{C}$ and $5{ }^{\circ} \mathrm{C} / \mathrm{min}$ heating rate. Conditions: LGO $0.1 \mathrm{~mol} / \mathrm{L}, \mathrm{H}_{2} \mathrm{SO}_{4} 4.9$ $\mathrm{mol} / \mathrm{L}$

The result is presented in Figure 7 (b). All the yield profiles showed the maximum in the calculated time range. In spite of the same final temperature $\left(90^{\circ} \mathrm{C}\right)$, the maximum HMF yield varied over a wide range of 9.5$67.6 \%$-C. Holding time even at $20^{\circ} \mathrm{C}$ had a substantial influence. The maximum yield of $35.5 \%$-C decreased to 
$25.4 \%$-C by the difference of holding time from zero to $10 \mathrm{~min}$ with $5{ }^{\circ} \mathrm{C} / \mathrm{min}$ heating rate. To ensure the calculation results, experiments were carried out with 10 min holding time at $20^{\circ} \mathrm{C}$ and $5{ }^{\circ} \mathrm{C} / \mathrm{min}$ heating rate. The experimental and calculation results agreed well as shown in Figure 7 (b). The formation of DP2 at low temperature thus significantly influences the available maximum HMF yield. To suppress the influence, rapid heating soon after dissolving LGO into the $\mathrm{H}_{2} \mathrm{SO}_{4}$ aqueous solution is effective for this reaction system.

\section{Conclusions}

In this study, aqueous phase conversion of LGO into HMF was investigated using microtube reactor and high concentration $\mathrm{H}_{2} \mathrm{SO}_{4}$ as catalyst. The $\mathrm{HMF}$ yield reached $61.5 \%$-C with the reaction selectivity over $80 \%$ in a few minutes of reaction when used $4.9 \mathrm{~mol} / \mathrm{L} \mathrm{H}_{2} \mathrm{SO}_{4}$ at $90^{\circ} \mathrm{C}$. The experiment with glucose and fructose under the same experiment failed to achieve such high yield, indicating suitability of LGO as HMF feedstock for achieving the high yield under atmospheric pressure with short reaction time. Kinetic analysis of the experimental results revealed that rapid heating after mixing LGO with the acidic solution was essential to suppress side reaction that formed undesired degradation products directly generated from LGO.

\section{Acknowledgements}

This work was financially supported by MEXT/JSPS KAKENHI Grant No. JP16K06845. Xin Huang also thanks China Scholarship Council (Grant number 201606420055) for the financial support.

\section{References}

Cao, F. T., J. Schwartz, D. J. McClelland, S. H. Krishna, J. A. Dumesic, and G. W. Huber; "Dehydration of Cellulose to Levoglucosenone Using Polar Aprotic Solvents," Energy Environ. Sci., 8, 1808-1815 (2015)

E4tech, RE-CORD, and WUR ; "From the Sugar Platform to Biofuels and Biochemicals," Final Report for the European Commission, Contract No. ENER/C2/4232012/SI2.673791 (2015)

He, J., M. Liu, K. Huang, T. W. Walker, C. T. Maravelias, J. A. Dumesic, and G. W. Huber; "Production of Levoglucosenone and 5-hydroxymethylfurfural from Cellulose in Polar Aprotic Solvent-Water Mixtures," Green Chem., 19, 3642-3653 (2017)

Huang, X., S. Kudo, and J.-i. Hayashi; "Two-step Conversion of Cellulose to Levoglucosenone Using Updraft Fixed Bed Pyrolyzer and Catalytic Reformer," Fuel Process Technol, 191, 29-35 (2019a)

Huang, X., S. Kudo, J. Sperry, and J.-i. Hayashi; "Clean Synthesis of 5-Hydroxymethylfurfural and Levulinic Acid by Aqueous Phase Conversion of Levoglucosenone over Solid Acid Catalysts" ACS Sustainable Chem Eng, 7, 5892-5899 (2019b)

Kawamoto, H., S. Saito, W. Hatanaka, and S. Saka; "Catalytic Pyrolysis of Cellulose in Sulfolane with Some Acidic Catalysts," J. Wood Sci., 53, 127-133 (2007)

Krishna, S. H., T. W. Walker, J. A. Dumesic, and G. W. Huber; "Kinetics of Levoglucosenone Isomerization," ChemSusChem, 10, 129-138 (2016)

Krishna, S. H., K. Huang, K. J. Barnett, J. He, C. T. Maravelias, J. A. Dumesic, G. W. Huber, M. De bruyn, and B. M. Weckhuysen; "Oxygenated Commodity Chemicals from Chemo-catalytic Conversion of Biomass Derived Heterocycles," AIChE J., 64, 1910-1922 (2018)

Kudo, S., N. Goto, J. Sperry, K. Norinaga, and J.-i. Hayashi; "Production of Levoglucosenone and Dihydrolevoglucosenone by Catalytic Reforming of Volatiles from Cellulose Pyrolysis Using Supported Ionic Liquid Phase," ACS Sus. Chem. Eng., 5, 1132-1140 (2017)

Mukherjee, A., M.-J. Dumont, and V. Raghavan; "Review: Sustainable Production of Hydroxymethylfurfural and Levulinic Acid: Challenges and Opportunities," Biomass Bioenergy, 72, 143-183 (2015)

Muranaka, Y., H. Nakagawa, R. Masaki, T. Maki, and K. Mae; "Continuous 5-Hydroxymethylfurfural Production from Monosaccharides in a Microreactor," Ind. Eng. Chem. Res., 56, 10998-11005 (2017)

Qi, L., Y. F. Mui, S. W. Lo, M. Y. Lui, G. R. Akien, and I. T. Horváth; "Catalytic Conversion of Fructose, Glucose, and Sucrose to 5-(Hydroxymethyl)furfural and Levulinic and Formic Acids in $\gamma$-Valerolactone As a Green Solvent," ACS Catal, 4, 1470-1477 (2014)

Rackemann, D. W. and W. O. S. Doherty; "The conversion of lignocellulosics to levulinic acid" Biofuels, Bioprod Biorefin, 5, 198-214 (2011)

Saha, B. and M. M. Abu-Omar; "Advances in 5Hydroxymethylfurfural Production from Biomass in Biphasic Solvents," Green Chem., 16, 24-38 (2014)

Sherwood, J., M. De bruyn, A. Constantinou, L. Moity, C. R. McElroy, T. J. Farmer, T. Duncan, W. Raverty, A. J. Hunt, and J. H. Clark; "Dihydrolevoglucosenone (Cyrene) as a Bio-based Alternative for Dipolar Aprotic Solvents," Chem. Commun., 50, 9650-9652 (2014)

Shimanouchi, T., Y. Kataoka, T. Tanifuji, Y. Kimura, S. Fujioka, and K. Terasaka; "Chemical Conversion and Liquid-Liquid Extraction of 5-hydroxymethylfurfural from Fructose by Slug Flow Microreactor," AIChE J., 62, 2135-2143 (2016) 
van Putten, R. J., J. C. van der Waal, E. de Jong, C. B. Rasrendra, H. J. Heeres, and J. G. de Vries; "Hydroxymethylfurfural, a versatile platform chemical made from renewable resources" Chem Rev, 113, 14991597 (2013)

Yang, G., E. A. Pidko, and E. J. Hensen; "Mechanism of Brønsted acid-catalyzed conversion of carbohydrates" $J$ Catal 295, 122-132 (2012)

Ye, X.-n., Q. Lu, X. Wang, H.-q. Guo, M.-s. Cui, C.-q. Dong, and Y.-p. Yang; "Catalytic Fast Pyrolysis of Cellulose and Biomass to Selectively Produce Levoglucosenone Using Activated Carbon Catalyst" ACS Sustainable Chem Eng, 5, 10815-10825 (2017) 